\title{
TRPM2 Silencing Causes G2/M Arrest and Apoptosis in Lung Cancer Cells via Increasing Intracellular ROS and RNS Levels and Activating the JNK Pathway
}

\author{
Shekoufeh Almasia Clara Yu Long ${ }^{b} \quad$ Andra Stereab $^{\mathrm{b}} \quad$ Derek Richard Clements ${ }^{c}$ \\ Shashi Gujard,e Yassine El Hiani ${ }^{\text {b }}$ \\ aDepartments of Biology, Faculty of Medicine, Dalhousie University, Halifax, Canada, 'b Physiology and \\ Biophysics, Faculty of Medicine, Dalhousie University, Halifax, Canada, 'Department of Microbiology \\ and Immunology, Stanford University, Stanford, CA, USA, dPathology, Faculty of Medicine, Dalhousie \\ University, Halifax, Canada, eMicrobiology and Immunobiology, Faculty of Medicine, Dalhousie \\ University, Halifax, Canada
}

\section{Key Words}

Non-small cell lung cancer • TRPM2 • JNK • ROS

\begin{abstract}
Background/Aims: The oxidative stress sensor transient receptor potential melastatin-2 (TRPM2) ion channel has recently gained attention in many types of cancer. The lung tissue is highly susceptible to oxidative stress-mediated injury and diseases; therefore, we aimed to determine whether TRPM2 plays an essential role in protecting lung cancer cells from oxidative damage while promoting cancer cell survival and metastasis. Methods: We used two non-small cell lung (NSCLC) cell lines A549 and H1299 as a lung cancer model. We investigated the functional expression of TRPM2 using electrophysiology, GRT-PCR and Western blots. CFSE and flow cytometry were used to study TRPM2 role in proliferation, cell cycle and apoptosis. Gap closure chambers and Three-Tiered Chemotaxis Chamber were used to study the role of TRPM2 in metastasis. SCID mice were used to study the role of TRPM2 in lung tumor growth and metastasis. Results: We demonstrate that TRPM2 is functionally expressed in NSCLC cells and that its downregulation significantly inhibits cell proliferation and promotes apoptosis. These results were concomitant with an induction in DNA damage and $\mathrm{G} 2 / \mathrm{M}$ cell cycle arrest. TRPM2 silencing inhibits also lung cancer cells invasion ability and alters EMT processes. Mechanistically, TRPM2 downregulation causes an increase in the intracellular levels of reactive oxygen (ROS) and nitrogen (RNS) species, which in turn causes DNA damage and JNK activation leading to G2/M arrest, and an ultimate cell death. Finally, TRPM2 downregulation suppresses the growth of human lung tumour xenograft in SCID mice and TRPM2 depleted tumours exhibited a significant reduction in the mRNA expression level
\end{abstract}




\section{Cellular Physiology Cell Physiol Biochem 2019;52:742-757

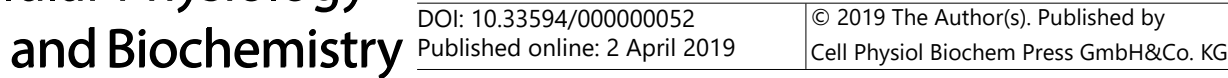 \\ Almasi et al.: TRPM2 in Lung Tumor Growth and Invasion}

of EMT markers compared to the control tumors. Conclusion: Our data provide new insights on the functional expression of TRPM2 in lung cancer, its essential role in tumour growth and metastasis through the control of JNK signaling pathway, and that TRPM2 could be exploited for targeted lung cancer therapies.

(C) 2019 The Author(s). Published by Cell Physiol Biochem Press GmbH\&Co. KG

\section{Introduction}

Despite decades of research, technological advancement of early cancer detection and treatment, lung cancer remains the first leading cause of cancer-related death worldwide. Lung cancer generally consists of two main groups based on the cell types of origin - the small cell lung cancer (SCLC) and the non-small cell lung cancer (NSCLC). SCLC is also called oat cell cancer and represents $15 \%$ of the total lung cancers. SCLC often tends to develop early in life and is usually triggered by environmental factors such as smoking. However, NSCLC counts for $85 \%$ of the total lung cancer cases, and only $15 \%$ of the diagnosed patients will survive over 5 years [1].

Currently, the most common treatment option for lung cancer patients is the whole lung resection (pneumonectomy) followed by chemotherapy [2]. However, this therapeutic approach is often unsuccessful in late-stage lung cancer patients; thus, limiting the patient overall survival and quality of life [3]. Therefore, identification of the novel effective therapeutic targets is of the most important action in the fight against lung cancer treatment.

In the last decades, ion channels have been demonstrated to contribute to the acquirement of cellular hallmarks of cancer, and currently, represent a fruitful area for clinical investigations [4]. Among many ion channels, the transient receptor potential channel melastatin-2 (TRPM2) is emerging as a substantial therapeutic target in several types of cancers [5]. TRPM2 is identified as a non-selective cation channel, permeable to calcium, and considered as the main redox sensor in mammalian cells due to its unique activation pathway by ADP-ribose (ADPR) [6, 7]. TRPM2 is ubiquitously expressed with paradoxical functions in human normal and diseased tissues $[8,9]$. Indeed, in normal cells, TRPM2 activation has been shown to play an essential role in cell death [10]. In contrast, in a diseased state such as cancer, TRPM2 appears to have a protective role against apoptosis [5]. For instance, TRPM2 is essential in maintaining the survival of neuroblastoma, prostate, and gastric cancer cells [11-13]. It is suggested that calcium influx through TRPM2 is a key factor in the activation of many intracellular pathways which affects the critical steps of tumorigenesis such as cell proliferation, apoptosis, migration and invasion [14-16]. Among many of these intracellular pathways, c-Jun NH2-terminal kinase (JNK) activation cascade has been recently introduced as a key transduction signaling pathway modulated by TRPM2 to control cancer cell survival [11]. JNK is a key member of the Mitogen-activated protein kinase (MAPK) signaling pathways, whose role in tumorigenesis remains debatable. For instance, in NSCLC biopsies, JNK was shown to promote tumor cell proliferation and motility; however, JNK has also been reported to inhibit lung oncogenesis by enhancing apoptosis, suppressing tumor cell metastasis and inhibiting RAS-induced tumor formation $[17,18]$. This controversy might be derived from its differential response to various activation signals; JNK, in fact, can function as both, pro- and anti-tumorigenic factor based on its activation pathway [19].

The expression of TRPM2 in lung tumors has been detected, and the association of TRPM2 expression with the prognosis of lung adenocarcinoma has been described [20]; however, the role of TRPM2 in NSCLC survival and metastasis has been never described. Similarly, its contribution to the development and progression of lung tumors is unknown. To explore these issues, we have detected the functional expression of TRPM2 in two NSCLC and further investigated its effects on the cell proliferation, apoptosis, migration, and invasion. Our major findings include: 1) TRPM2 downregulation inhibits cell survival/invasion, and lung tumor growth; 2) TRPM2 downregulation induces the ROS/RNS-mediated activation of JNK signaling pathway and promotes DNA damage and 


\section{Cellular Physiology Cell Physiol Biochem 2019;52:742-757 \\ \begin{tabular}{ll|l} 
DOl: 10.33594/000000052 & $\begin{array}{l}\text { O } 2019 \text { The Author(s). Published by } \\
\text { Cell Physiol Biochem Press GmbH\&Co. KG }\end{array}$
\end{tabular} \\ Almasi et al.: TRPM2 in Lung Tumor Growth and Invasion}

G2/M arrest. Altogether, our results provide new evidences for the potential therapeutic impact of targeting TRPM2 towards the improvement of lung cancer treatment.

\section{Materials and Methods}

\section{Cell culture}

Human immortalized cancer cell lines, HEK239 (ATCC-CRL-1573), A549 (ATCC-CRM-CCL-185) and NCI-H1299 (ATCC-CRL-5803) were purchased from ATCC and cultured in their specific medium supplemented with heat-inactivated fetal bovine serum (FBS; Gibco, Life Technologies, 16000036) and 20 $\mu \mathrm{g} / \mathrm{ml}$ penicillin/streptomycin antibiotic (Gibco; Life Technologies, 15070063). Cultured cells were grown at $37^{\circ} \mathrm{C}$ and $5 \% \mathrm{CO}_{2}$ incubator.

\section{Preparation of theTRPM2 stable gene-knockdown cell lines}

TRPM2-specific lentiviral shRNA constructs (LV-pLKO.1-shTRPM2) were purchased from Dharmacon (TRCN0000044152: AAGTAGGAGAGGATGTTCAGG, TRCN0000044154: ATCCTCATCCAGTATGTACTC). The pLKO.sh.hSC plasmid was used for the generation of scrambled cells (Addgene 46896: GAGGGCCTATTTCCCATGATT). Lentiviral particles were produced according to the protocol of the $3^{\text {rd }}$ generation lentiviral packaging system [21]. Briefly, HEK-293 cells were co-transfected with PPAX2 (6 $\mu \mathrm{g})$, MD2G $(3 \mu \mathrm{g})$ and LV-pLKO.1-shRNA $(6 \mu \mathrm{g})$ plasmids in the presence of PEI transfection reagent (Sigma). After 24 hours, the lentiviral particles were collected, filtered (Millex-GS; $0.22 \mu \mathrm{m}$ sterile filter) and stored at $-80^{\circ} \mathrm{C}$.

To prepared TRPM2 knockdown cancer lung cells, 0.2 million cells were seeded in 6-well plates and grown for 24 hours. On the day of the transduction experiment, cell medium was replaced with $500 \mu \mathrm{L}$ of lentivirus aliquot and $8 \mu \mathrm{g} / \mathrm{mL}$ of Sequebrene (Sigma) diluted in the cell-specific medium with the total volume of $2 \mathrm{~mL}$. Transduced cells were incubated at $37^{\circ} \mathrm{C}$ and $5 \% \mathrm{CO}_{2}$ for 72 hours. $1 \mu \mathrm{g} / \mathrm{mL}$ Puromycin was used to select transduced cells. Later on, knockdown efficiency was examined using RT-qPCR and western blot analyses.

\section{RT-qPCR analysis}

TRIzol-based RNA extraction was performed using the Invitrogen RNA Purification kit. Following spectrophotometric quantification, $2 \mu \mathrm{g}$ of RNA was to synthesize complementary DNA (cDNA) according to the Super Script ${ }^{\circledR}$ II First-Strand Synthesis protocol (Invitrogen). Gene expression was quantified by realtime PCR using gene-specific primers. The primers were designed in our lab and ordered from Invitrogen, the sequences of the used primers are:

GAPDH: CTGAAGAGCTGCTTCACCAA/ATGGTGCTGTCCTTGACAAC, TRPM2: AAGTACGTCCGAGTCTCCCA/CGGAAAATGCTCTTCAGCCG, E-Cadherin: GAAGGTGACAGAGCCTCTGAT/GATCGGTTACCGTGATCAAAATC, N-Cadherin: CCTTTCAAACACAGCCACGG/TGTTTGGGTCGGTCTGGATG, Snail: ACCACTATGCCGCGCTCTT/GGTCGTAGGGCTGCTGGAA, Slug: CTGGTCAAGAAGCATTTCAACGCC/AAAGAGGAGAGAGGCCATTGGGTA, Vimentin: TCTACGAGGAGGAGATGCGG/GGTCAAGACGTGCCAGAGAC, Fibronectin: CCATCGCAAACCGCTGCCAT/AACACTTCTCAGCTATGGGCTT.

The gene expression data were analyzed according to the Livak and Schmittgen's $2^{-\Delta \Delta C \mathrm{C}}$ method and normalized to the reference gene, 3-phosphate dehydrogenase (GAPDH) [21].

Whole-cell patch clamp

The whole-cell patch clamp method was used to record the TRPM2 current in TRPM2-KD and scrambled cells at $21-25^{\circ} \mathrm{C}$ with the voltage ramp of -50 to $50 \mathrm{mV}$ as described before [11]. Cells were diluted in standard extracellular saline buffer: $140 \mathrm{mM} \mathrm{NaCl}, 2.8 \mathrm{mM} \mathrm{KCl}, 1 \mathrm{mM} \mathrm{CaCl}, 2 \mathrm{mM} \mathrm{MgCl}, 10 \mathrm{mM}$ glucose, and $10 \mathrm{mM}$ HEPES- $\mathrm{NaOH}$ (pH 7.2 adjusted with $\mathrm{NaOH}$ ) and perfused with pipette-filling solution 


\section{Cellular Physiology Cell Physiol Biochem 2019;52:742-757 \begin{tabular}{ll|l} 
and Biochemistry & DOl: 10.33594/000000052 & Published online: 2 April 2019
\end{tabular} \\ Almasi et al.: TRPM2 in Lung Tumor Growth and Invasion}

containing $140 \mathrm{mM}$ cesium-glutamate, $8 \mathrm{mM} \mathrm{NaCl}, 1 \mathrm{mM} \mathrm{MgCl}, 10 \mathrm{mM}$ HEPES cesium KOH (pH 7.2, adjusted with cesium-KOH) containing 2mM ADPR (TRPM2 activator) [22].

\section{Western blotting}

Western blot analysis was used to determine the protein levels of different markers in human cancer cell lines. Proteins were extracted from cells using 1x RIPA buffer $(20 \mathrm{mM}$ Tris- $\mathrm{HCl}$ (pH 7.5), $150 \mathrm{mM} \mathrm{NaCl}$, $1 \mathrm{mM} \mathrm{Na2-EDTA}, 1 \mathrm{mM}$ EGTA, 1\% NP-40, 1\% sodium deoxycholate, $2.5 \mathrm{mM}$ sodium pyrophosphate, $1 \mathrm{mM}$ $\beta$-glycerophosphate, $1 \mathrm{mM} \mathrm{Na} 3 \mathrm{VO}, 1 \mu \mathrm{g} / \mathrm{ml}$ leupeptin) followed by sonication and centrifugation of the Lysate. The concentration protein in the solution was quantified using the BCA protein quantification kit (Thermofisher Scientific). Twenty $\mu$ g of each protein sample were separated based on their molecular weight on the polyacrylamide gel and transferred onto a $0.45 \mu \mathrm{m}$ PVDF membrane (BioRad). A $5 \%$ milk solution (milk powder dissolved in 1x TBST (137 mM NaCl, $2.7 \mathrm{mM} \mathrm{KCl}, 19 \mathrm{mM}$ Tris-base, 0.1\% TWEEN 20)) was used to block the membranes for $1 \mathrm{hr}$ at room temperature. Blots were washed with $1 \mathrm{x}$ PBS and incubated with primary antibodies (anti-GAPDH: sc-365062, anti- $\beta$-Actin: 3700s, anti-TRPM2: A300-414A-2, antiSAPK/JNK: 9252s, anti-phospho-SAPK/JNK: 4668s, anti-cleaved-Caspase-7: 9494s, anti-Vimentin: 5741S, anti-phospho-Histone H2A.X: $9718 \mathrm{~S}$, anti-Cyclin B1: 4138S) overnight in $4^{\circ} \mathrm{C}$. Antibody dilution buffer (5\% BSA and $0.01 \%$ TWEEN 20 in $1 \mathrm{x}$ TBS) primary was used to dilute primary antibodies. Twenty-four hours later, membranes were washed with $1 \mathrm{x}$ PBS and incubated with the isotype-specific fluorescent secondary antibody (1:5000; Goat-Anti-Mouse, Goat-Anti-Rabbit; Mandel Scientific) for 1 hour at room temperature. The Li-Cor Odyssey 9120 infrared imager was used to scan the membranes; the protein band intensity was quantified by ImageJ $1.48 \mathrm{v}$ software.

\section{CFSE Cell proliferation assay}

Carboxyfluorescein succinimidyl ester (CFSE) staining was performed to measure cell proliferation rate. Cell suspensions were incubated with $100 \mu \mathrm{L}$ of $2.5 \mu \mathrm{M}$ CFSE dye for $15 \mathrm{~min}$ at $37^{\circ} \mathrm{C}$ in the dark. Afterward, stained cells were cultured in 12 -well plates and grown at $37^{\circ} \mathrm{C}$ and $5 \% \mathrm{CO}_{2}$ for $3-4$ days. $\mathrm{BD}$ FACSCalibur $^{\text {tm }}$ (Spectron Corporation) Flow cytometer was used to read samples at a wavelength of $488 \mathrm{~nm}$. The decreased fluorescent intensity indicates the high proliferation rate.

\section{Cell cycle analysis}

To identify the percentage of the cell population in each phase of the cell cycle Propidium Iodide (PI) staining was used. Cells were cultured at $37^{\circ} \mathrm{C}$ and $5 \%$ for 72 hours. On the day of the experiment, cells were collected and washed with 1x PBS twice followed by fixation with chilled $70 \%$ ethanol. The fixed cells were stored at $4{ }^{\circ} \mathrm{C}$ overnight. On the next day, cells were washed twice with $1 \mathrm{x}$ PBS and incubated with $1 \mathrm{~mL}$ PI solution $(100 \mu \mathrm{g} / \mathrm{mL}$ PI and $50 \mu \mathrm{g} / \mathrm{mL}$ RNase A in $1 \mathrm{x}$ PBS) for an hour at room temperature in the dark. Flow cytometry analysis was done the above cytometer at 488 wavelengths $(\mathrm{nm})$. The data were processed in Flowing 2.5.1 software.

\section{Annexin v/7-and binding assay}

To determine apoptosis and necrosis level in cancer cells Annexin V/7-AAD binding assay was utilized. Cells were cultured in 6-well plates and grown for 72 hours at $37^{\circ} \mathrm{C}$ and $5 \% \mathrm{CO}_{2}$. On the day of the experiment, cells were washed with $1 \mathrm{x}$ Annexin buffer (0.1M HEPES/NaOH (pH 7.4) $1.4 \mathrm{M} \mathrm{NaCl}, 25 \mathrm{mM} \mathrm{CaCl}$ ) and incubated with $12.5 \mu \mathrm{g} / \mathrm{mL}$ AnnexinV-fluorescein isothiocyanate (AnnexinV, Alexa Fluor 488; Invitrogen) and $20 \mu \mathrm{g} / \mathrm{mL}$ 7-AAD solution (7-amino-actinomycin D, Biolegend, $650 \mathrm{~nm}$ ) for $15 \mathrm{~min}$ at room temperature in the dark. Cells were suspended in $1 \mathrm{~mL}$ of $1 \mathrm{x}$ Annexin buffer and the fluorescent intensity was quantified using the cytometer. The data analysis was performed by FCS Express 30 Plus software.

\section{Intracellular reactive oxygen species detection assay}

The total level of intracellular ROS was measured by H2DCFDA (2',7' -dichlorofluorescein diacetate) staining. Seventy-two hours after cells were cultured, they were collected and washed with 1x PBS twice and stained with $100 \mu \mathrm{l} \mathrm{H2DCFDA}$ (Thermofisher, D399) solution (1:200 in 1x PBS) for 1 hour at $37^{\circ} \mathrm{C}$ in the dark. After washing cells with $1 \mathrm{x}$ PBS twice, they were diluted in $1 \mathrm{~mL}$ of $1 \mathrm{x}$ PBS. Samples were read by the flow cytometer at $488 \mathrm{~nm}$; data were analyzed by Flowing 2.5 .1 software. (note: positive control cells were treated with $500 \mathrm{nM} \mathrm{H}_{2} \mathrm{O}_{2}$ for 30 min in $37^{\circ} \mathrm{C}$ incubator prior the staining.) 


\section{\begin{tabular}{ll|l} 
Cellular Physiology & Cell Physiol Biochem 2019;52:742-757 \\
\hline DOl: 10.33594/000000052 & O 2019 The Author(s). Published by \\
Cand Biochemistry & Published online: 2 April 2019 & Cell Physiol Biochem Press GmbH\&Co. KG
\end{tabular} \begin{tabular}{ll|l} 
and Biochemistry & $\begin{array}{l}\text { DOl: 10.33594/000000052 } \\
\text { Published online: } 2 \text { April } 2019\end{array}$ & $\begin{array}{l}\text { @ } 2019 \text { The Author(s). Published by } \\
\text { Cell Physiol Biochem Press GmbH\&Co. KG }\end{array}$ \\
\cline { 2 - 3 } Almasi et al: TRPM2 in Lung Tumor Growth and Invasion
\end{tabular}}

Mitochondrial superoxide detection assay

The mitochondrial superoxide levels were measured using MitoSOX Red staining. Seventy-two hours after cell culture, cells were collected and washed twice with $1 \mathrm{x}$ PBS. Afterward, suspended cells were stained with $100 \mu \mathrm{l}$ of $5 \mu \mathrm{M}$ MitoSOX in $1 \mathrm{x}$ HBSS for $10 \mathrm{~min}$ at $37^{\circ} \mathrm{C}$ in the dark. After washing cells twice with $1 \mathrm{x}$ HBSS, they were diluted in $1 \mathrm{ml}$ of $1 \mathrm{x}$ HBSS and read at $586 \mathrm{~nm}$ by the flow cytometer.

\section{Intracellular nitric oxide detection assay}

DAF-FM staining was performed to detect the cytoplasmic nitric oxide (NO) level. Cells were cultured for 72 hours flowed by staining with $100 \mu \mathrm{L}$ of $5 \mu \mathrm{M}$ DAF-FM in $1 \mathrm{x}$ HBSS for 10 min at $37^{\circ} \mathrm{C}$ in the dark. Later, cells were washed with $1 \mathrm{x}$ HBSS and diluted in $1 \mathrm{~mL}$ of $1 \mathrm{x}$ HBSS and read at $586 \mathrm{~nm}$ using the flow cytometer.

\section{Gap closure or wound healing assay}

Cancer cells motility was examined using 2D gap closure assay. Cells were cultured in 2-well culture inserts placed in $\mu$-Dish ${ }^{35 m m}$ (ibidi). The next day, cells were incubated with $10 \mu \mathrm{g} / \mathrm{mL}$ mitomycin to inhibit cell growth at $37^{\circ} \mathrm{C}$ in $5 \% \mathrm{CO}_{2}$ incubator for $2 \mathrm{hrs}$. Later, the inserts were removed, and gaps were photographed with a conventional 10x phase-contrast objective lens. Photos were recorded every 6 hrs until they have been filled in the control cells. The gaps' width was analyzed by ImageJ software and plotted in SigmaPlot12.3 software.

\section{Cell migration and invasion assay}

To measure the in vitro cell migration and invasion abilities, the A3BP48 Three-Tiered Chemotaxis Chamber (Neuro Probe) assay was performed. The lower chamber's wells were filled with $25 \mu \mathrm{L}$ of complete cell-specific medium containing 10\% FBS and $50 \mu \mathrm{L}$ of the cell suspension (cells were suspended in FBS free medium) were loaded in the upper chamber's wells. Two part of the chamber was separated with a $25 \times 80$ $\mathrm{mm}$ polycarbonate filters ( $8 \mu \mathrm{m}$ pores). The prepared chamber was incubated at $37^{\circ} \mathrm{C}$ and $5 \% \mathrm{CO}_{2}$ overnight. Twenty-four hours later, unmigrated cells were removed from the top of the membrane; membrane was stained by the Diff-Quik ${ }^{\mathrm{TM}}$ Stain kit (Siemens) and let dry. The stained membrane was mounted on the slide by mounting buffer (Fisher chemical) and covered by a coverslip. Slides were photographed with a conventional 20x phase-contrast objective lens; images were analyzed by Image software and data were plotted by SigmaPlot12.3 software. (Note: for examining cell invasion, polycarbonate filters were coated with $0.1 \%$ gelatin 24 hours before the experiment.)

\section{Animal study}

The tumor formation capability of TRPM2-KD cells was compared with control cells by in vivo analysis. Four million cells were subcutaneously injected to the left flank of SCID male mice and tumors were measured every three days for around 1.5 months. At the end of the experiment, mice were sacrificed, and tumors were extracted. Tumor growth rate, final tumor volume, and final tumor weight were plotted using GraphPad Prism 6 software. RT-qPCR was performed on the extracted tumors to compare the expression level of EMT markers between two tumor groups.

\section{Gene expression data}

The TRPM2 microarray expression data of normal and lung cancer tissues were obtained from the ion channel gene expression databases in lung cancer patients provided by Ko JH et al. in 2014 [20]. The tissue expression level of TRPM2 has been studied in 60 extracted lung tumor and normal samples from NSCL patients. Data was processed, and graphs were plotted in GraphPad Prism 6 software.

\section{Reagents}

Cell culture mediums, FBS, PBS, HBSS, and penicillin/streptomycin antibiotic were purchased from Invitrogen/Thermofisher scientific. Anistomycin (JNK activator) and SP600125 (JNK activator) were bought from Sigma-Aldrich. 


\section{Cellular Physiology Cell Physiol Biochem 2019;52:742-757 \\ \begin{tabular}{ll|l} 
DOl: 10.33594/000000052 & $\begin{array}{l}\text { O } 2019 \text { The Author(s). Published by } \\
\text { Cell Physiol Biochem Press GmbH\&Co. KG }\end{array}$ \\
\cline { 2 - 3 }
\end{tabular} \\ Almasi et al.: TRPM2 in Lung Tumor Growth and Invasion}

Statistical analysis

All experiments were executed at least three times; one biological replicate was represented in each figure. Statistical analysis was done for three independent experiments and student's $t$-test was used to compare the significant difference between control and TRPM2-KD groups. Asterisks represent the degree of significance: $p$ - values: $n . s=p \geq 0.05,{ }^{*} p=0.01$ to $0.05,{ }^{* *} p=0.001$ to $0.01,{ }^{* * *}=p<0.001$.

\section{Results}

TRPM2 is up-regulated in lung tumor tissues and functionally expressed in NSCLC cell lines

First, we analyzed the available database to explore the gene expression profile of TRPM2 in lung adenocarcinomas. Analysis of the paired normal and tumor tissues from 60 non-smoker lung adenocarcinoma patients showed that TRPM2 is upregulated in lung cancer tissues compared to the normal lung tissues (Fig. 1A), suggesting a potential role of TRPM2 in lung tumor progression. Therefore, we next aimed to explore the TRPM2 functional expression in two well-known NSCLC cell lines, A459, and H1299. To specifically target TRPM2 channel, we have used two TRPM2-specific shRNA clones (TRPM2-KD1 and KD2) and evaluated the channel function in TRPM2-KD and scrambled (Scr.) cells using whole-cell patch clamp method [11]. RT-qPCR and WB analyses confirmed the efficiency of TRPM2 silencing in both cell lines (Fig. 1B and 1C). In our experimental conditions, internal perfusion of $2 \mathrm{mM}$ ADPR in scrambled A459 and H1299 cells elicited a linear I/V relationship current, while only small currents have been recorded in TRPM2-KD cells (Fig. 1D and 1E). These data indicate that TRPM2 is highly expressed in lung tumor tissues, and that TRPM2 is functionally expressed in NSCLC cell lines as a plasma membrane ion channel.

TRPM2 downregulation in lung cancer cells inhibits cell proliferation and promotes apoptosis due to DNA damage-dependent G2/M arrest

After establishing the functional expression of TRPM2 in lung cancer cells, we next investigated its biological impact on cell survival. Therefore, the CFSE assay was performed to study the proliferation of both scrambled and TRPM2-KD cells. Our results showed that TPPM2 depleted A459 and H1299 cells exhibited a slower growth rate than scramble cells (Fig. 2A and 2B), which was correlated with the G2/M cell cycle arrest (Fig. 2C and 2E). These effects were also concomitant with the increased cell death as indicated by the shift of cell population from left to the right along Annexin axis (Fig. 2G) which was further confirmed by an increase in the protein level of cleaved-caspase-7 in TRPM2-KD cells (Fig. 2H). Since G2/M arrest is usually associated with DNA damage [23], we have extended our investigation to examine whether TRPM2-KD induces DNA damage (phospho-Histone H2A.X) [24] and G2/M arrest (Cyclin B1) [25] markers simultaneously. Under our experimental conditions, TRPM2-KD cells exhibited a decrease in the protein level of cyclin B1 and an increase in phospho-Histone H2A.X level (Fig. 2D and 2F). Altogether, our data indicate a pro-survival role for TRPM2 in lung cancer cells, probably through its role in the control of DNA integrity and cell cycle progression.

TRPM2 depleted cells lost their in vitro metastatic ability

Given the tremendous impact of tumor metastasis on the lung cancer mortality [26], we investigated the role of TRPM2 in the in vitro metastatic potential of lung cancer cells. The gap closure and multi-well chamber chemotaxis assays were performed to examine motility and migration/invasion abilities of TRPM2-KD and scramble cells. As Fig. 3 shows, cells motility was obviously reduced in TRPM2-KD cells compared to A459 and H1299 scramble cells (Fig. $3 \mathrm{~A}$ and $3 \mathrm{~B}$ ). We have also observed a lower number of migrated and invaded TRPM2-KD cells in a multi-well chemotaxis assay (Fig. 3C and 3D). In accordance with our functional results, we examined the mRNA and protein expression levels of the Epithelial-Mesenchymal 


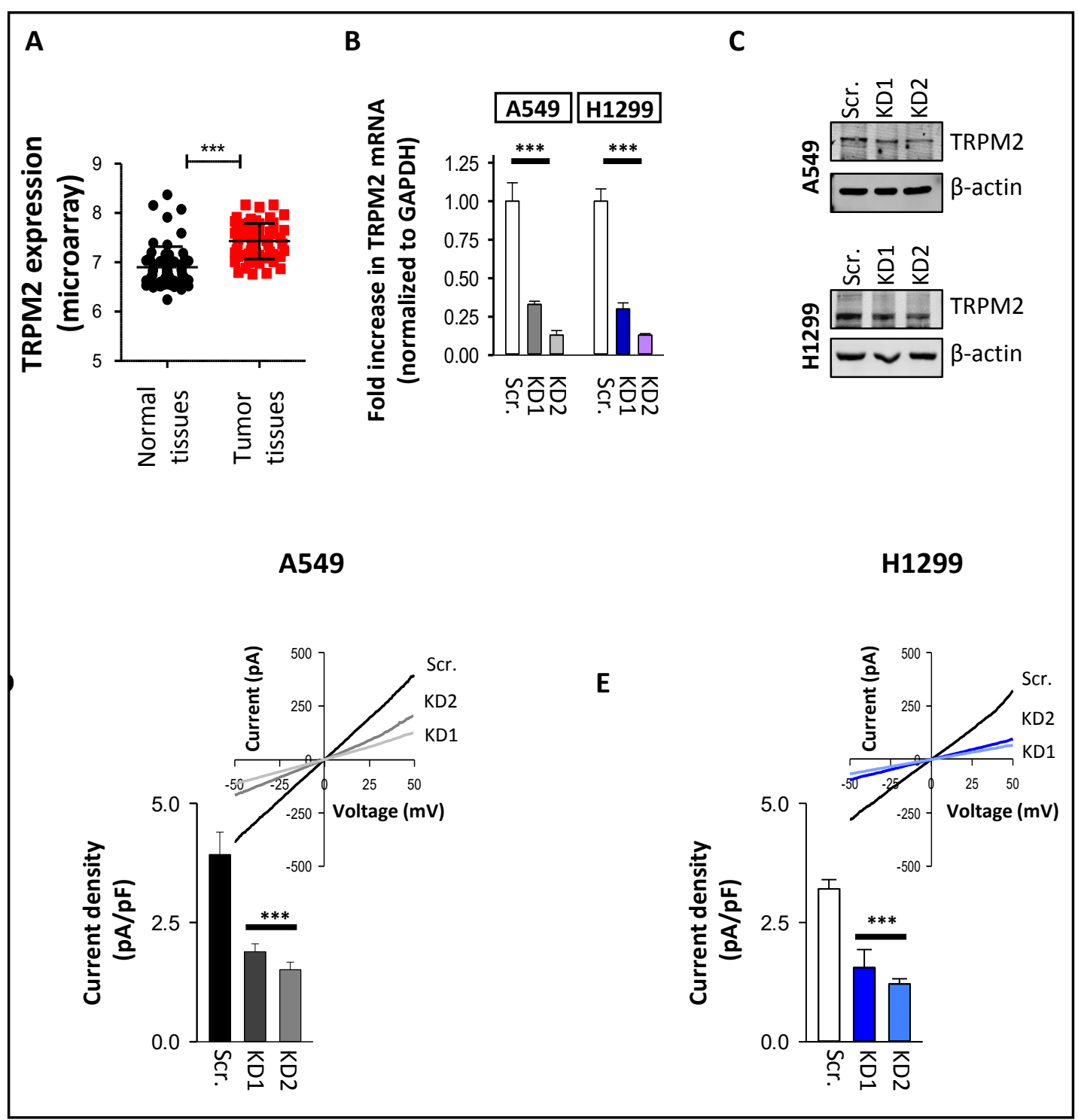

Fig. 1. TRPM2 expression is upregulated in lung tumor tissues and its downregulation in NSCLC cells reduces ADPR current. (A) microarray analysis of TRPM2 expression in normal and malignant lung tissues [24] (B \& C) RT-qPCR and western blot analyses of TRPM2 expression level in scramble and TRPM2-KD NSCLC cells. (D \& E) Whole-cell patch clamp analysis of TRPM2 channel activity in the presence of $2 \mathrm{mM}$ ADPR (t test vs scr. ${ }^{* * *}, \mathrm{p}<0.001 ;{ }^{* *}, \mathrm{p}<0.01 ;{ }^{*} \mathrm{p}<0.05$ ).

Transition (EMT)-related markers; TRPM2 downregulation caused a significant decrease in all tested EMT markers (Fig. 3E and 3F). These data indicate the involvement of TRPM2 in the control of lung cancer cells metastasis, probably through EMT modulation.

TRPM2 depleted lung cancer cells accumulate reactive oxygen and nitrogen species which activate the JNK signaling pathway

To investigate the mechanism behind the observed impact of TRPM2 downregulation in lung cancer cells, we examined the intracellular Reactive Oxygen (ROS) and Reactive Nitrogen (RNS) species in TRPM2-KD cells, as the important inducers of the DNA damage and cell cycle arrest $[27,28]$. Our results show that TRPM2 silencing in A459 and H1299 lung cancer cells causes a significant accumulation of total ROS (Fig. 4A and 4B), mitochondrial ROS (Fig. 4C and 4D), and RNS (Fig. 4E and 4F), as indicated by the histogram's shift to the 
A

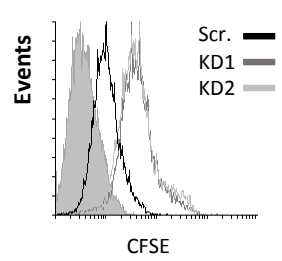

C
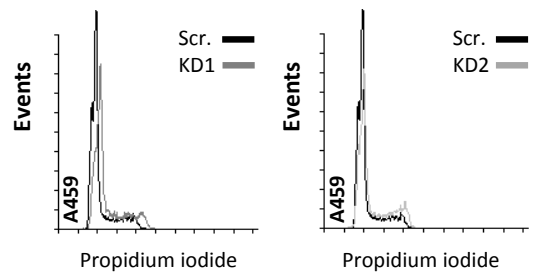

E
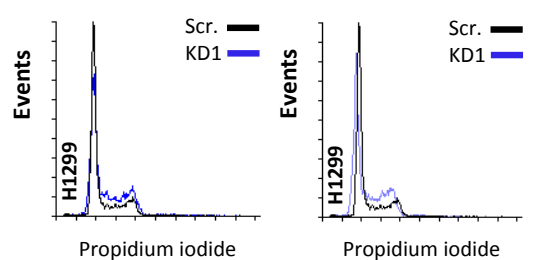

G
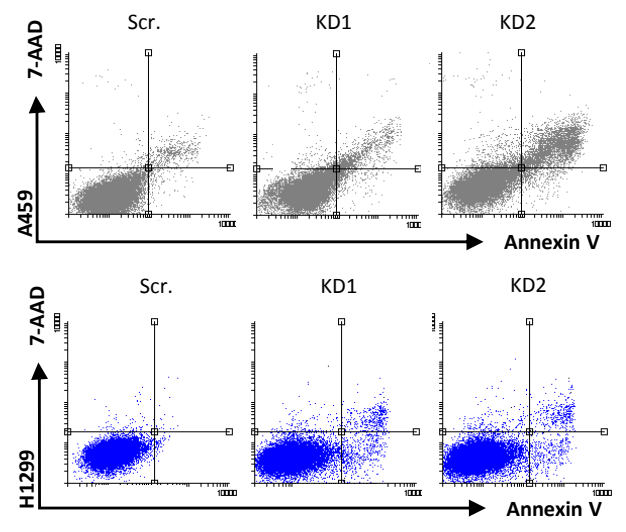

B

H1299

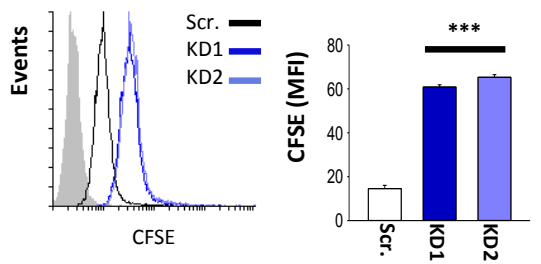

D
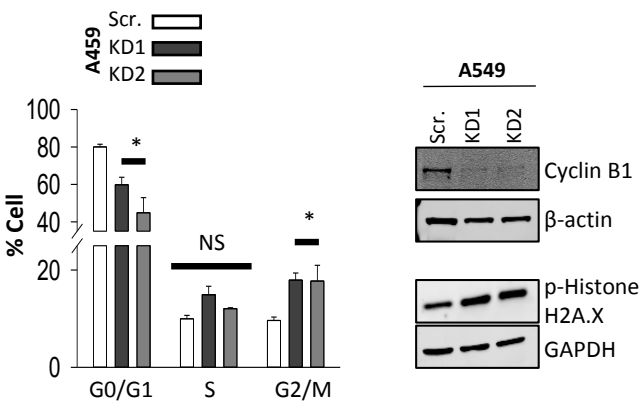

$\mathbf{F}$
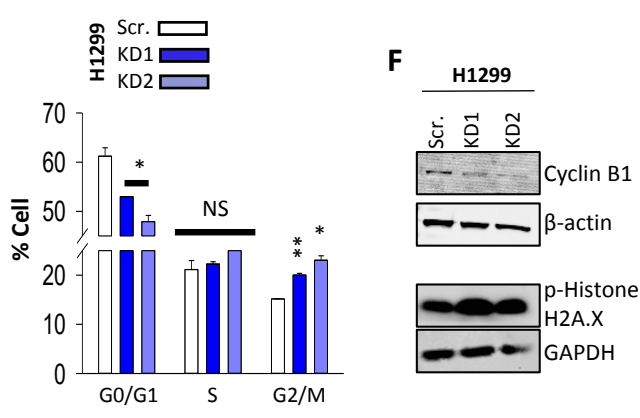

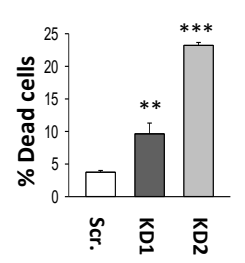

H

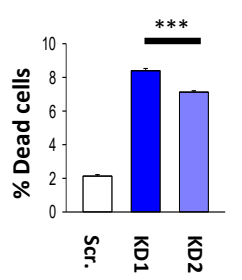

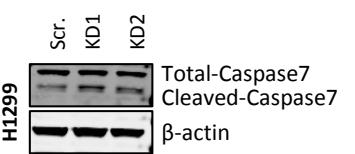

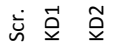

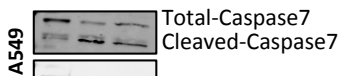

Fig. 2. TRPM2 downregulation inhibits NSCLC cells growth at G2/M and promotes apoptosis. (A \& B) Histogram and bar graph presentation of CFSE proliferation analysis in A549 scramble and TRPM2 KD cells. (C \& E) Cell cycle analysis of A549 cells by propidium iodide staining, results are summarized in a corresponding bar chart. (D \& F) Western blot analysis of DNA damage and G2/M arrest markers (p-Histone H2A.X and Cyclin B1) (G) Annexin V/7-AAD staining of apoptotic and necrotic cells, percentage of dead cells were calculated and presented as a bar graph $(\mathrm{H})$ Western blot analysis of cleaved caspase 7 ( $\mathrm{t}$ test vs scr. ${ }^{* * *}, \mathrm{p}<0.001 ;{ }^{* *}, \mathrm{p}<0.01 ;{ }^{*} \mathrm{p}<0.05$ ). 


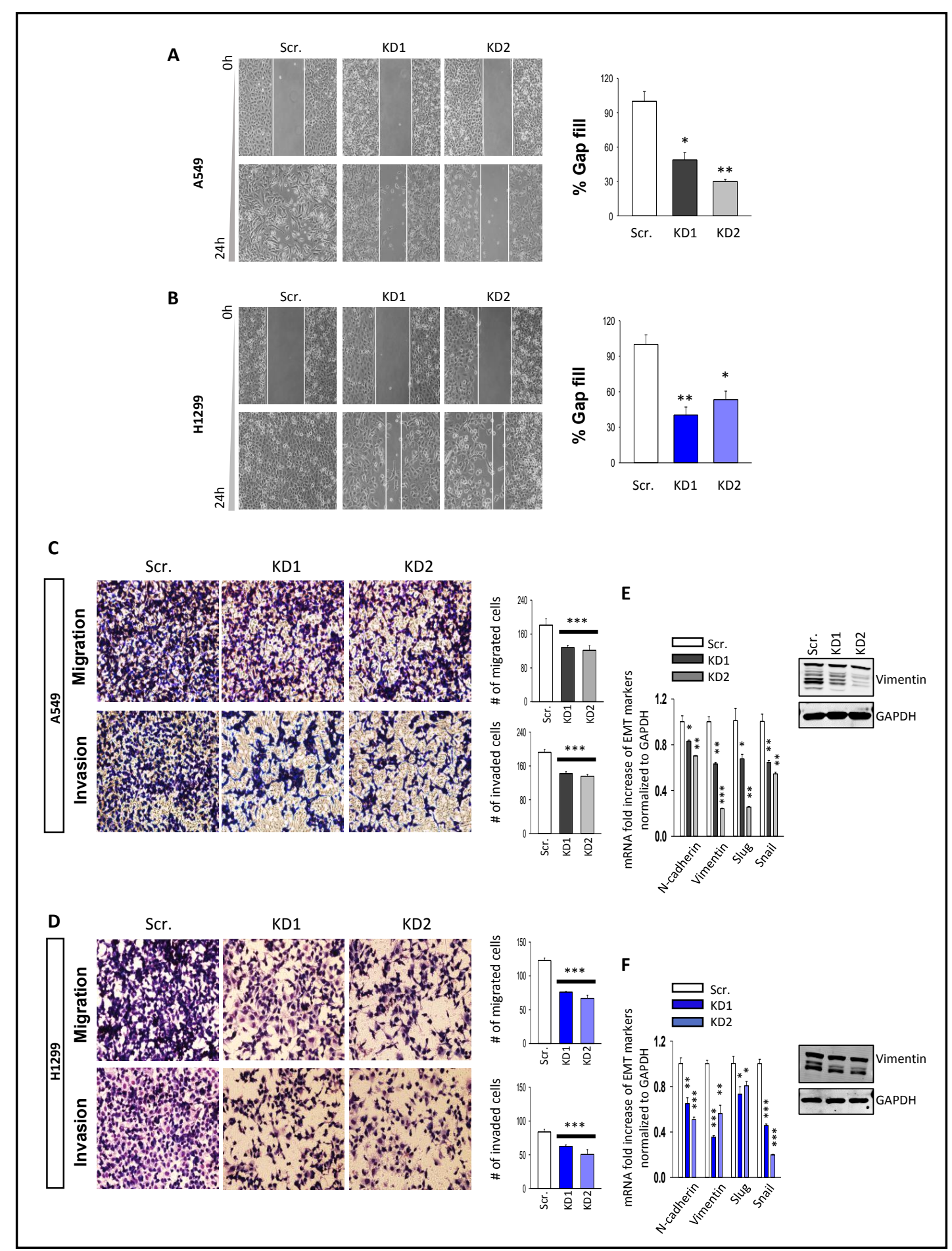

Fig. 3. TRPM 2 downregulation inhibits the in vitro inavsion ability of NSCLC cells. (A \& B) Gap closure (wound healing assay) migration analysis of A549 cells before and after TRPM2 silencing. Bar graph shows the statistical analysis of resulted data. (C \& D) The quantitative analysis of migration and invasion ability of A549 scramble and TRPM2 KD cells. (E \& F) RT-qPCR and western blot analysis of the expression level of EMT markers ( $t$ test vs scr. ${ }^{* * *}, \mathrm{p}<0.001 ;{ }^{* *}, \mathrm{p}<0.01 ;{ }^{*} \mathrm{p}<0.05$ ). 
A549

A

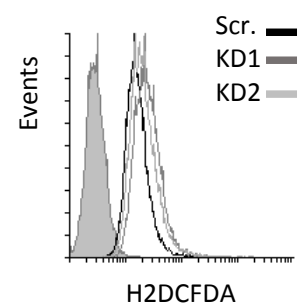

C

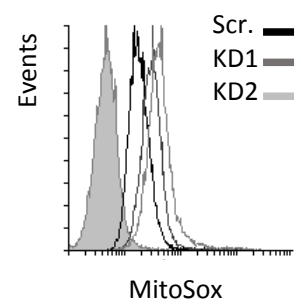

E

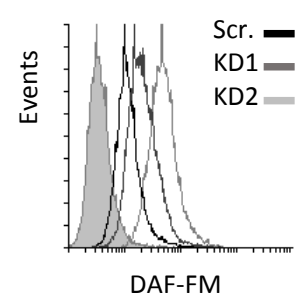

B
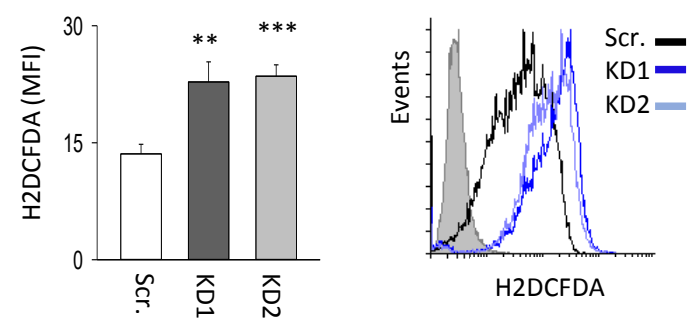

D
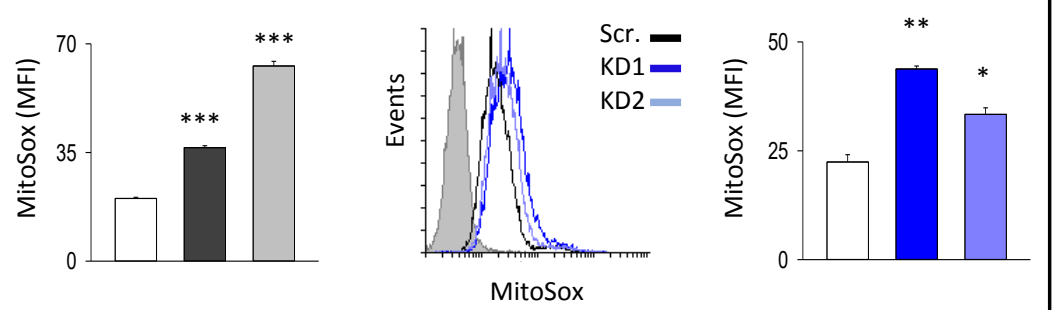

$\mathbf{F}$

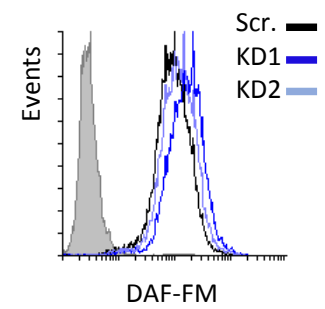

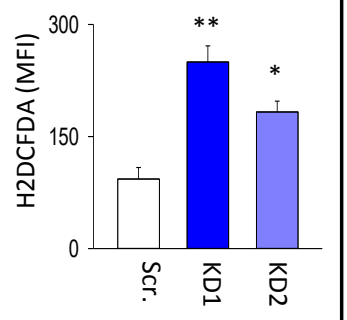

H1299

Fig. 4. TRPM 2 downregulation is associated with an increase in intracellular ROS and NOS levels. (A \& B) Representative histograms and bar graphs of intracellular ROS level in lung cancer scramble cells and TRPM2-KD cells (C \& D) Mitochondrial ROS production level in A549 and H1299 cells before and after TRPM2 depletion (E \& F) The level of accumulated Nitric Oxide in TRPM2-KD cells in compare to wildtype lung cancer cells ( $t$ test vs scr. ${ }^{* * *}, \mathrm{p}<0.001 ;{ }^{* *}, \mathrm{p}<0.01$; $^{*} \mathrm{p}<0.05$ ).

right in TRPM2-KD cells and bar graphs. Given that increased intracellular ROS and RNS in mammalian cells have been shown to activate JNK signaling pathway which plays a key role in the induction of cell death and the alteration of metastasis in lung cancer cells $[17,18,29$, $30]$, we examined the protein expression level of phospho-JNK in scrambled and TRPM2KD cells. Our data indicated an increase in the protein level of phospho-JNK in TRPM2-KD cells (Fig. 5A and 5C), suggesting that JNK activation is likely contributing to the TRPM2 KD-mediated cell death and metastasis inhibition in NSCLC cell lines. The involvement of JNK pathway in TRPM2 silencing impact on lung cancer cells' survival and metastasis was further investigated through pharmacological modulation of JNK pathway; first, we attempt to confirm whether passive activation of JNK in A459 and H1299 control cells can mimic TRPM2 KD effects. For this, control cells were treated with JNK activator Anisomycin [31]. 


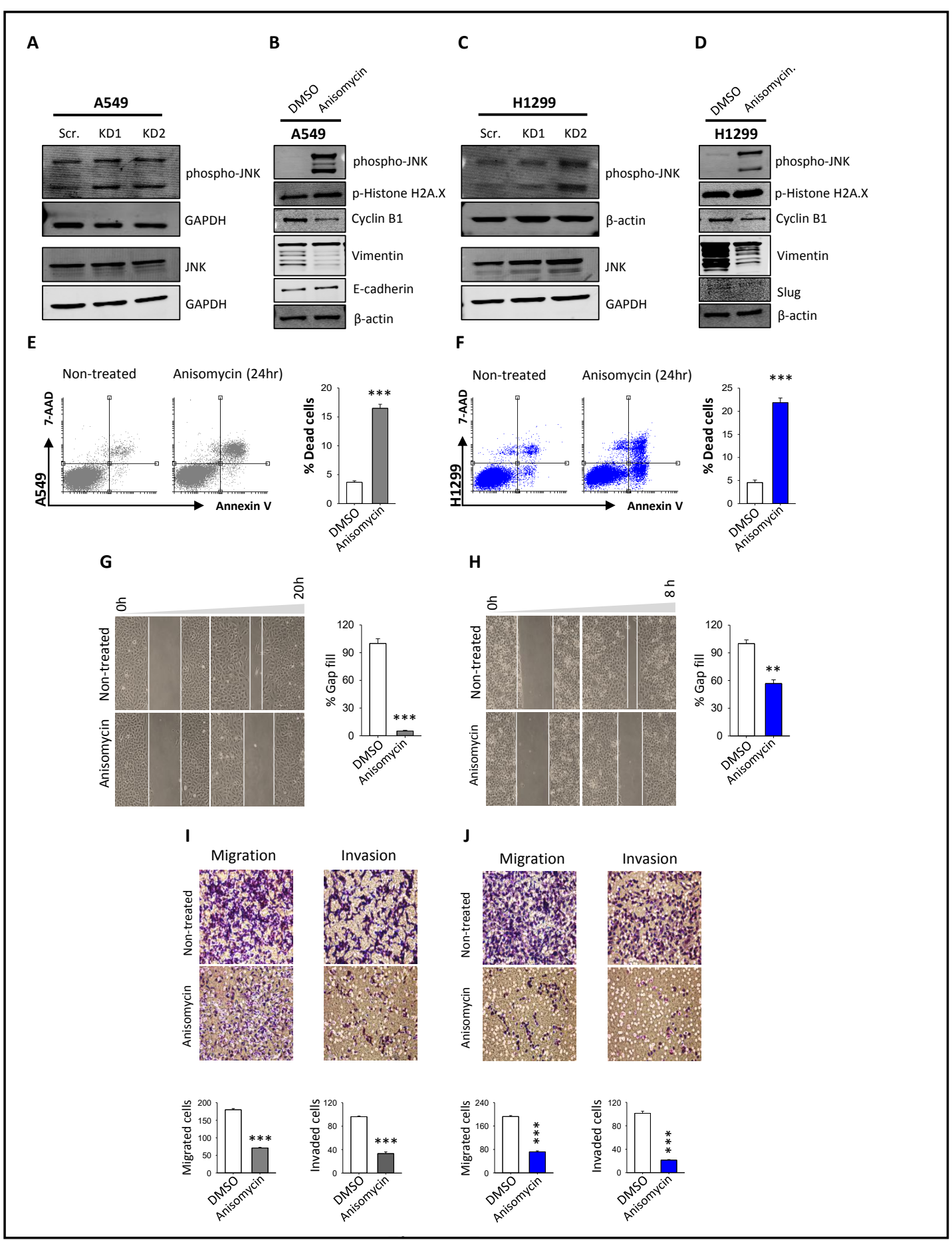

Fig. 5. JNK activation is contributing to TRPM2 KD-mediated NSCLC death and invasion-blocking. (A \& C) Western blot analysis of JNK and pJNK protein level in control and TRPM2-KD cells (B \& D) Protein expression level of pJNK, p-Histone H2A.X, Cyclin B1 and vimentin in NSCLC control cells, with and without treatment with $1 \mu \mathrm{g} / \mathrm{mL}$ Anisomycin for $24 \mathrm{hrs}$ (E \& F) Annexin V/7-AAD staining of apoptotic and necrotic cells in both Anisomycin ( $1 \mu \mathrm{g} / \mathrm{mL}$ Anisomycin for $24 \mathrm{hrs}$ ) treated and non-treated cells; percentages of dead cells are presented as bar graphs ( $\mathrm{G} \& \mathrm{H}$ ) Gap closure analysis of cell motility in the presence and absence of $1 \mu \mathrm{g} / \mathrm{mL}$ Anisomycin (I \& J) The quantitative analysis of migration and invasion ability of Anisomycin treated and non-treated cells after $16 \mathrm{hrs}$ incubation ( $\mathrm{t}$ test vs scr. ${ }^{* * *}, \mathrm{p}<0.001 ;{ }^{* *}, \mathrm{p}<0.01 ;^{*} \mathrm{p}<0.05$ ). 


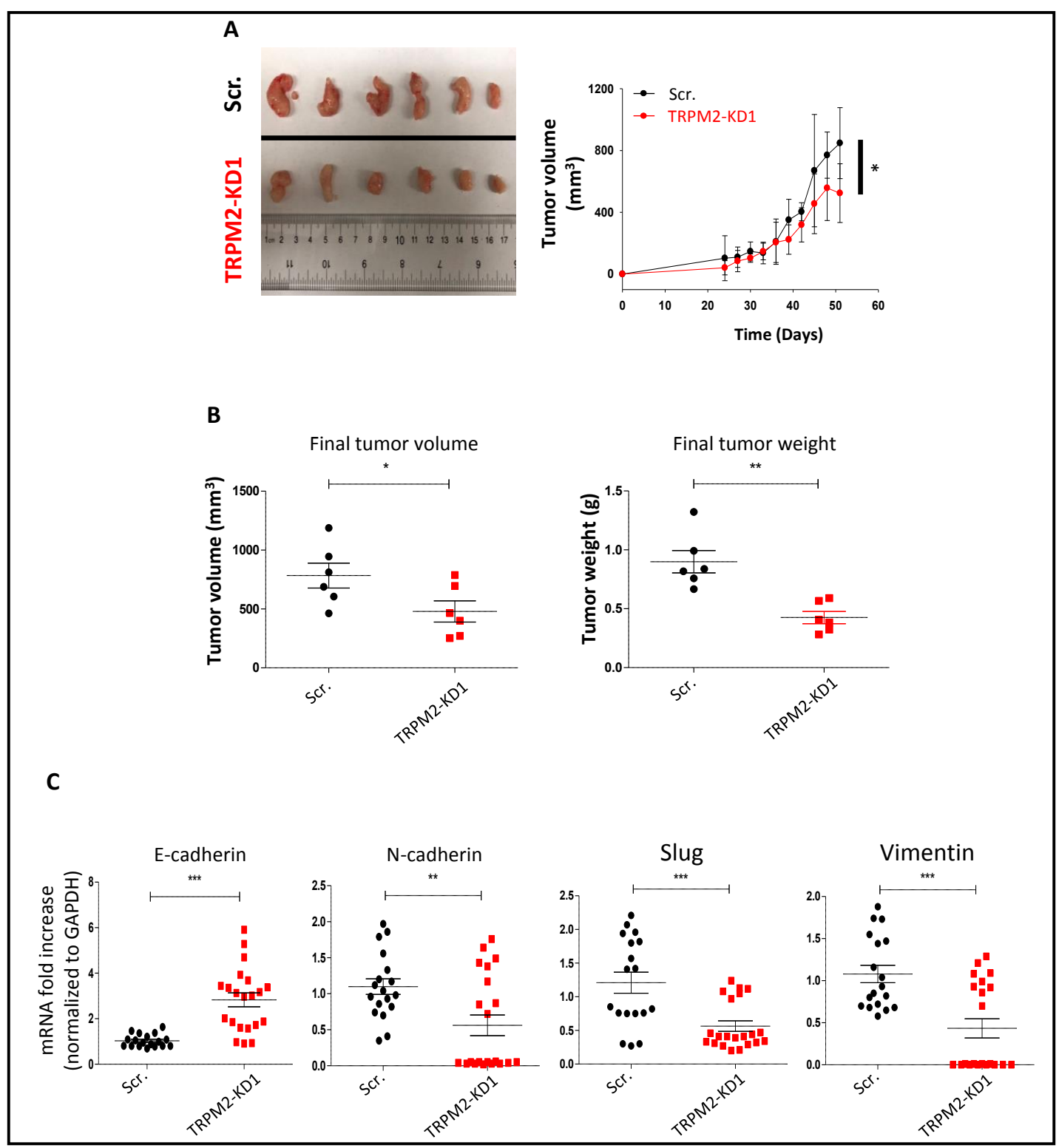

Fig. 6. TRPM2 downregulation reduces NSCLC tumor growth ability in SCID mice. (A) Representative in vivo image and the growth rate of scrambled and TRPM2-KD1 A549 tumours in NOD/SCID mice. Tumours were started to measure three weeks post subcutaneous injection every 3 days for around 6 weeks. Tumors were extracted and the final measurement of tumours volume and weight (B) as well as RT-qPCR analysis of EMT markers expression in tumors (C) were plotted ( $t$ test vs. scr. ${ }^{* * *}, \mathrm{p}<0.001{ }^{* *}, \mathrm{p}<0.01{ }^{*}, \mathrm{p}<0.05$ ).

As expected, JNK activator led to an elevation in the signal level of phospho-JNK protein as well as an increase in the protein expression of both DNA damage (phospho-Histone H2A.X) and G2/M arrest (Cyclin B1) markers (Fig. 5B and 5C). Anisomycin treatment also reversed the expression of metastatic markers, as reflected by a reduction in vimentin and slug along with a substantial augmentation in the E-cadherin level, highlighting the potential role of JNK in the ability of invasion of A459 and H1299 cells. Furthermore, A459 and H1299 cells treatment with Anisomycin enhanced apoptosis (Fig. 5E and 5F) and inhibited lung cancer cells metastatic ability (Fig. 5G-J). Second, we examined whether JNK inhibition can withstand TRPM2 KD effects. For this, TRPM2 depleted A459 and H1299 were treated with SP600125 JNK inhibitor [32]. Results indicate that SP600125 can partially restore TRPM2 KD cell proliferation and rescue cells from enhanced mortality. SP600125 also rescue the 


\section{Cellular Physiology Cell Physiol Biochem 2019;52:742-757 \\ \begin{tabular}{ll|l} 
DOl: 10.33594/000000052 & $\begin{array}{l}\text { O } 2019 \text { The Author(s). Published by } \\
\text { Cell Physiol Biochem Press GmbH\&Co. KG }\end{array}$ \\
\cline { 2 - 3 }
\end{tabular} \\ Almasi et al.: TRPM2 in Lung Tumor Growth and Invasion}

inhibition of motility in TRPM2 KD cells (unshown data). Taken together, these data indicate that TRPM2 KD-mediated NSCLC death and invasion-blocking likely involves JNK signaling.

TRPM2 downregulation inhibits tumor growth ability of lung cancer cells in the xenograft NOD/SCID mice model

To further validate our in vitro growth results, two groups of SCID mice were subcutaneously injected with 4 million scrambled or TRPM2-KD A549 cells. The tumor was sized every three days for seven weeks, and data were plotted in a line graph. The experiment was terminated by sacrificed animals and extracting tumors. The final tumor volumes and weights were measured and plotted. As shown in figure 6, tumor growth ability of TRPM2KD cells significantly decreased in comparison to scramble A549 lung cancer cells (Fig. 6A and 6B). Furthermore, RT-qPCR was performed on the extracted mRNA samples from both scramble and TRPM2-KD tumors. Results indicated that mRNA expression level of many EMT markers has been reversed in TRPM2 depleted lung tumors (Fig. 6C). In overall, both our in vitro and in vivo results demonstrated that TRPM 2 is contributing to lung cancer cells growth and metastasis.

\section{Discussion}

Accumulating studies have shown that TRPM2 is highly expressed in a number of malignancies including lung cancer, suggesting that it plays a role in promoting tumors growth, and its targeting may be a novel therapeutic approach [5, 20]. In this study, TRPM2 was downregulated in two NSCLC cell lines using lentiviral shRNA to explore its role in cancer cell survival, migration, invasion and tumor growth. The results of this study indicate the impact of TRPM2 inhibition on the reduction of the cell survival, metastasis and tumor growth, and the enhancement of the ROS and RNS generation. Specifically, we found that TRPM2 silencing reduces cell survival through the induction of G2/M arrest and the promotion of DNA damage and apoptosis. Our data also demonstrated the significant impact of TRPM2 downregulation on the inhibition of the in vitro metastatic ability of NSCLC cell lines through alternating the EMT processes, reflected by a reduction in the mRNA and protein levels of the key EMT markers. The underlying mechanism for the anti-survival effect of TRPM2 silencing is related to an elevation in the ROS and RNS generation, and the further activation of the JNK signaling pathway. The function of JNK signaling in cell cycle arrest, apoptosis, and tumor metastasis is well documented [17-19, 31, 33-36]. Our findings are consistent with the reports that JNK promotes DNA damage response in many types of cancer [37], and that its activation can act as tumor suppressor [38]. Our study also indicated that the induction of the ROS and RNS generation might contribute to TRPM2 KD-mediated DNA damage and cell death. Indeed, ROS and RNS are often increased in malignant cells, playing a key role in the transduction pathways and promoting cancer cell survival and metastasis $[39,40]$. However, their excessive accumulation increases cancer cell susceptibility to oxidative stress-mediated cell death [41]. Given the available knowledge, it is tempting to speculate that TRPM2 KD-mediated ROS and RNS accumulation acts as an activation signal for the JNK pathway which further caused cell cycle arrest and death in lung cancer cells. This hypothesis is highly consistent with the previous reports demonstrating the direct link between an elevated ROS and JNK-mediated G2/M arrest and cell death [42, 43].

Our results also demonstrated the impact of TRPM2 inhibition on the reduction of the migration and invasion capabilities of lung cancer cells, the major obstacle against the successful cancer therapies as well as the major contributor to lung cancer mortality. This is consistent with a recent publication reporting that TRPM2 targeting inhibits the invasion ability of pancreatic ductal adenocarcinoma while TRPM2 overexpression fosters their aggressiveness [44]. These findings further confirm the TRPM2 potential role as a novel therapeutic target to improve cancer therapy. 
Despite extensive effort, understanding the underlying mechanisms of TRPM2-mediated cancer cell survival still requires further investigations. However, based on the available knowledge along with our recent findings, the complete procedure of the TRPM2 protective effect on lung cancer cells can be possibly explained as follows. The favorable elevation of non-toxic concentrations of ROS activates TRPM2 to elicit oxidative stress responses to relive cellular stress and protect cells. This can be due, in part, to TRPM2's role in cancer cells bioenergetic, through its role in sustaining mitochondrial calcium uptake; however, in TRPM2 depleted cells the threshold levels of ROS and RNS seem to reach toxic concentrations, probably as a result of autophagic processes alteration. Indeed, we have previously shown that TRPM2 inhibition dampens autophagy and promotes mitophagy in gastric cancer cells [11]. In addition, Dr Miller's lab has demonstrated that TRPM2 depletion induces the generation of both total and mitochondrial ROS in neuroblastoma [12, 45]. Therefore, it is tempting to speculate that TRPM2 depletion in lung cancer inhibits autophagy and causes the accumulation of unhealthy mitochondria which, in turn causes ROS accumulation and subsequently, damage to intercellular macromolecules and organelles. One of the most common consequences of oxidative and nitrosative is DNA damage, which can cause cell cycle arrest and activate DNA repair system. In addition, the accumulated ROS and RNS can also activate JNK signaling pathway to promote cell cycle arrest, and inhibits DNA repair. In other words, TRPM2 KD-mediated DNA repair failure in highly damaged cells will lead to apoptosis and cancer cell death.

\section{Conclusion}

We have demonstrated that TRPM2 is involved in the viability, metastasis and tumor growth capability of lung cancer cells. Further studies are required to uncover the fundamental mechanisms through which TRPM2 inhibition potentiate JNK activation and ROS/NO generation. Given the fact that TRPM2 is upregulated in many types of cancers, including lung tumor tissues $[5,20]$ and given its essential role for lung tumor progression, further researches focus on the development of an effective and specific TPRM2 inhibitor would be a promising approach in advancing cancer treatment.

\section{Acknowledgements}

This work was supported by Dalhousie Medical Research Foundation Capital Equipment Grant and Dalhousie Physiology and Biophysics StartUp funds. S.A. designed and executed each experiment and wrote the paper. C.Y.L. helped for cell transfection and immunoblotting. A.M.S. \& D.R.C. provided assistance with animal experiments; S.G. made important comments; Y.E.H. conceived the overall study, experimental design and wrote the manuscript.

\section{Disclosure Statement}

The authors have no potential conflict of interest regarding this publication.

\section{References}

- 1 Miller KD, Siegel RL, Lin CC, Mariotto AB, Kramer JL, Rowland JH, Stein KD, Alteri R, Jemal A: Cancer treatment and survivorship statistics, 2016. CA Cancer J Clin 2016;66:271-289.

Cooper S, Spiro SG: Small cell lung cancer: treatment review. Respirology 2006;11:241-248.

- 3 Islami F, Torre LA, Jemal A: Global trends of lung cancer mortality and smoking prevalence. Transl. Lung Cancer Res 2015;4:327-338. 


\section{Cellular Physiology Cell Physiol Biochem 2019;52:742-757 \begin{tabular}{c|c|c|}
\cline { 2 - 2 } aOI: 10.33594/000000052 & O 2019 The Author(s). Published by \\
\hline
\end{tabular} and Biochemistry Published online: 2 April 2019 Cell Physiol Biochem Press GmbH\&Co. KG \\ Almasi et al.: TRPM2 in Lung Tumor Growth and Invasion}

- 4 Litan A, Langhans SA: Cancer as a channelopathy: ion channels and pumps in tumor development and progression. Front Cell Neurosci 2015;9:86.

- 5 Sumoza-Toledo A, Espinoza-Gabriel MI, Montiel-Condado D: Evaluation of the TRPM2 channel as a biomarker in breast cancer using public databases analysis. Bol Med Hosp Infant Mex 2016;73:397-404.

6 Perraud AL, Fleig A, Dunn CA, Bagley LA, Launay P, Schmitz C, Stokes AJ, Zhu Q, Bessman MJ, Penner R, Kinet JP, Scharenberg AM: ADP-ribose gating of the calcium-permeable LTRPC2 channel revealed by Nudix motif homology. Nature 2001;411:595-599.

- 7 Kolisek M, Beck A, Fleig A, Penner R: Cyclic ADP-ribose and hydrogen peroxide synergize with ADP-ribose in the activation of TRPM2 channels. Mol Cell 2005;18:61-69.

8 Orfanelli U, Wenke AK, Doglioni C, Russo V, Bosserhoff AK, Lavorgna G: Identification of novel sense and antisense transcription at the TRPM2 locus in cancer. Cell Res 2008;18:1128-1140.

- 9 Yamamoto S, Shimizu S: Targeting TRPM2 in ROS-Coupled Diseases. Pharmaceuticals 2016;9:pii:E57.

10 Sun L, Yau HY, Wong WY, Li RA, Huang Y, Yao X: Role of TRPM2 in H(2)O(2)-induced cell apoptosis in endothelial cells. PloS One 2012;7:e43186.

11 Almasi S, Kennedy BE, El-Aghil M, Sterea AM, Gujar S, Partida-Sanchez S, El Hiani Y: TRPM2 channelmediated regulation of autophagy maintains mitochondrial function and promotes gastric cancer cell survival via the JNK-signaling pathway. J Biol Chem 2018;293:3637-3650.

- 12 Bao L, Chen SJ, Conrad K, Keefer K, Abraham T, Lee JP, Wang J, Zhang XQ Hirschler-Laszkiewicz I, Wang HG, Dovat S, Gans B, Madesh M, Cheung JY, Miller BA: Depletion of the Human Ion Channel TRPM2 in Neuroblastoma Demonstrates Its Key Role in Cell Survival through Modulation of Mitochondrial Reactive Oxygen Species and Bioenergetics. J Biol Chem 2016;291:24449-24464.

- 13 Zeng X, Sikka SC, Huang L, Sun C, Xu C, Jia D, Abdel-Mageed AB, Pottle JE, Taylor JT, Li M: Novel role for the transient receptor potential channel TRPM2 in prostate cancer cell proliferation. Prostate Cancer Prostatic Dis 2010;13:195-201.

- 14 Chen SJ, Zhang W, Tong Q, Conrad K, Hirschler-Laszkiewicz I, Bayerl M, Kim JK, Cheung JY, Miller BA: Role of TRPM2 in cell proliferation and susceptibility to oxidative stress. Am J Physiol Cell Physiol 2013;304:C548560.

- 15 Hara Y, Wakamori M, Ishii M, Maeno E, Nishida M, Yoshida T, Yamada H, Shimizu S, Mori E, Kudoh J, Shimizu N, Kurose H, Okada Y, Imoto K, Mori Y: LTRPC2 Ca2+-permeable channel activated by changes in redox status confers susceptibility to cell death. Mol Cell 2002;9:163-173.

16 Sumoza-Toledo A, Penner R: TRPM2: a multifunctional ion channel for calcium signalling. J Physiol 2011;589:1515-1525.

- 17 Avisetti DR, Babu KS, Kalivendi SV: Activation of p38/JNK pathway is responsible for embelin induced apoptosis in lung cancer cells: transitional role of reactive oxygen species. PloS One 2014; 9:e87050.

- 18 Su JC, Lin KL, Chien CM, Lu CM, Chen YL, Chang LS, Lin SR: Novel indoloquinoline derivative, IQDMA, induces G(2)/M phase arrest and apoptosis in A549 cells through JNK/p38 MAPK signaling activation. Life Sci 2009;85:505-516.

19 Liu J, Lin A: Role of JNK activation in apoptosis: a double-edged sword. Cell Res 2005;15:36-42.

- $20 \mathrm{Ko} \mathrm{JH,} \mathrm{Gu} \mathrm{W,} \mathrm{Lim} \mathrm{I,} \mathrm{Bang} \mathrm{H,} \mathrm{Ko} \mathrm{EA,} \mathrm{Zhou} \mathrm{T:} \mathrm{Ion} \mathrm{channel} \mathrm{gene} \mathrm{expression} \mathrm{in} \mathrm{lung} \mathrm{adenocarcinoma:} \mathrm{potential}$ role in prognosis and diagnosis. PloS One 2014;9:e86569.

- 21 Livak KJ, Schmittgen TD: Analysis of relative gene expression data using real-time quantitative PCR and the 2(-Delta Delta C(T)) Method. Methods 2001;25:402-408.

22 Lange I, Yamamoto S, Partida-Sanchez S, Mori Y, Fleig A, Penner R: TRPM2 functions as a lysosomal Ca2+release channel in beta cells. Sci Signal 2009;2:ra23.

23 DiPaola RS: To arrest or not to G(2)-M Cell-cycle arrest. Commentary re: A. K. Tyagi et al., Silibinin strongly synergizes human prostate carcinoma DU145 cells to doxorubicin-induced growth inhibition, G(2)-M arrest, and apoptosis. Clin Cancer Res., 8: 3512-3519, 2002. Clin Cancer Res 2002;8:3311-3314.

- 24 Sharma A, Singh K, Almasan A: Histone H2AX phosphorylation: a marker for DNA damage. Methods Mol Biol 2012;920:613-626.

- 25 Mullers E, Silva Cascales H, Burdova K, Macurek L, Lindqvist A: Residual Cdk1/2 activity after DNA damage promotes senescence. Aging Cell 2017;16:575-584.

- 26 Riihimaki M, Hemminki A, Fallah M, Thomsen H, Sundquist K, Sundquist J, Hemminki K: Metastatic sites and survival in lung cancer. Lung Cancer 2014;86:78-84. 


\section{Cellular Physiology Cell Physiol Biochem 2019;52:742-757

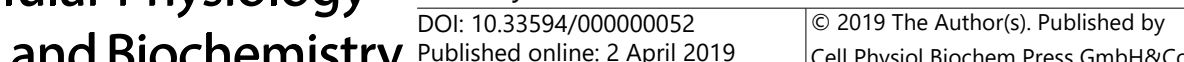 and Biochemistry Published online: 2 April 2019 Cell Physiol Biochem Press GmbH\&Co. KG \\ Almasi et al.: TRPM2 in Lung Tumor Growth and Invasion}

- 27 Dizdaroglu M, Jaruga P, Birincioglu M, Rodriguez H: Free radical-induced damage to DNA: mechanisms and measurement. Free Radic Biol Med 2002;32:1102-1115.

- 28 Zhao Y, Jiang W, Li B, Yao Q Dong J, Cen Y, Pan X, Li J, Zheng J, Pang X, Zhou H: Artesunate enhances radiosensitivity of human non-small cell lung cancer A549 cells via increasing NO production to induce cell cycle arrest at G2/M phase. Int Immunopharmacol 2011;11:2039-2046.

- 29 Okada M, Shibuya K, Sato A, Seino S, Watanabe E, Suzuki S, Seino M, Kitanaka C: Specific role of JNK in the maintenance of the tumor-initiating capacity of A549 human non-small cell lung cancer cells. Oncol Rep 2013;30:1957-1964.

30 Taylor CA, Zheng Q Liu Z, Thompson JE: Role of p38 and JNK MAPK signaling pathways and tumor suppressor p53 on induction of apoptosis in response to Ad-eIF5A1 in A549 lung cancer cells. Mol Cancer 2013;12:35.

- 31 Curtin JF, Cotter TG: Anisomycin activates JNK and sensitises DU 145 prostate carcinoma cells to Fas mediated apoptosis. Br J Cancer 2002;87:1188-1194.

32 Wang W, Shi L, Xie Y, Ma C, Li W, Su X, Huang S, Chen R, Zhu Z, Mao Z, Han Y, Li M: SP600125, a new JNK inhibitor, protects dopaminergic neurons in the MPTP model of Parkinson's disease. Neurosci Res 2004;48:195-202.

33 Bost F, McKay R, Bost M, Potapova O, Dean NM, Mercola D: The Jun kinase 2 isoform is preferentially required for epidermal growth factor-induced transformation of human A549 lung carcinoma cells. Mol Cell Biol 1999;19:1938-1949.

- 34 Shen HM, Liu ZG: JNK signaling pathway is a key modulator in cell death mediated by reactive oxygen and nitrogen species. Free Radic Biol Med 2006;40:928-939.

- 35 Xia HH, He H, De Wang J, Gu Q, Lin MC, Zou B, Yu LF, Sun YW, Chan AO, Kung HF, Wong BC: Induction of apoptosis and cell cycle arrest by a specific c-Jun NH2-terminal kinase (JNK) inhibitor, SP-600125, in gastrointestinal cancers. Cancer Lett 2006;241:268-274.

- 36 Ma X, Wang H, Ji J, Xu W, Sun Y, Li W, Zhang X, Chen J, Xue L: Hippo signaling promotes JNK-dependent cell migration. Proc Natl Acad Sci U S A 2017;114:1934-1939.

- 37 Picco V, Pages G: Linking JNK Activity to the DNA Damage Response. Genes Cancer 2013;4:360-368.

- 38 Tournier C: The 2 Faces of JNK Signaling in Cancer. Genes Cancer 2013;4:397-400.

- 39 Moldogazieva NT, Mokhosoev IM, Feldman NB, Lutsenko SV: ROS and RNS signalling: adaptive redox switches through oxidative/nitrosative protein modifications. Free Radic Res 2018;52:507-543.

- 40 Benedetti S, Nuvoli B, Catalani S, Galati R: Reactive oxygen species a double-edged sword for mesothelioma. Oncotarget 2015;6:16848-16865.

- 41 Di Meo S, Reed TT, Venditti P, Victor VM: Role of ROS and RNS Sources in Physiological and Pathological Conditions. Oxid Med Cell Longev 2016;2016:1245049.

- 42 Du L, Lyle CS, Obey TB, Gaarde WA, Muir JA, Bennett BL, Chambers TC: Inhibition of cell proliferation and cell cycle progression by specific inhibition of basal JNK activity: evidence that mitotic Bcl-2 phosphorylation is JNK-independent. J Biol Chem 2004;279:11957-11966.

- 43 Wu J, Sun J, Xue Y: Involvement of JNK and P53 activation in G2/M cell cycle arrest and apoptosis induced by titanium dioxide nanoparticles in neuron cells. Toxicol Lett 2010;199:269-276.

- 44 Lin R, Wang Y, Chen Q Liu Z, Xiao S, Wang B, Shi B: TRPM2 promotes the proliferation and invasion of pancreatic ductal adenocarcinoma. Mol Med Rep 2018;17:7537-7544.

45 Chen SJ, Hoffman NE, Shanmughapriya S, Bao L, Keefer K, Conrad K, Merali S, Takahashi Y, Abraham T, Hirschler-Laszkiewicz I, Wang J, Zhang XQ Song J, Barrero C, Shi Y, Kawasawa YI, Bayerl M, Sun T, Barbour M, Wang HG, et al.: A splice variant of the human ion channel TRPM2 modulates neuroblastoma tumor growth through hypoxia-inducible factor (HIF)-1/2alpha. J Biol Chem 2014;289:36284-36302. 